\title{
Targeted versus universal vaccination against hepatitis $B$ : A paradigm shift
}

Tepatitis B virus (HBV) is currently recognized as - a major cause of acute and chronic hepatitis, cirrhosis, and hepatic carcinoma. It is estimated that about 300 million people are chronic carriers worldwide. The epidemiology of hepatitis B is complex, but much has been learned during the past two decades. The spread of HBV in underdeveloped countries occurs predominately through vertical (perinatal) transmission, whereas in developed countries transmission occurs primarily through parenteral or sexual exposure. Commonly recognized risk factors include heterosexual activity with multiple partners, male homosexual activity, illicit drug use, and occupational exposure to blood $(1,2)$.

Hepatitis B has been notifiable in Canada since 
1969, and, although our country remains categorized as an area of low endemicity (fewer than $0.5 \%$ of residents are hepatitis B surface antigen positive), over the past decade, the number of reported cases of acute hepatitis B has progressively increased from five to 13 cases per 100,000 population (3). Although concerns may be raised about the accuracy of these passive surveillance data, a corresponding increase by a factor of three in the annual death rate due to hepatitis $B$ supports the contention that the increased incidence of hepatitis B is real and not a reporting phenomenon (3). Similarly, data collected from surveillance of viral hepatitis in four sentinel counties in the United States have demonstrated a significant increase in the proportion of cases of acute hepatitis B due to heterosexual exposure and parenteral illicit drug use during the 1980s (4). Overall, the estimated incidence of acute hepatitis B in the United States has risen from 55 to 63 per 100,000 between 1981 and 1987 (5).

The first vaccine against human hepatitis $\mathrm{B}$ became commercially available in 1982 and represented a major milestone in medicine. The initial strategy for prevention of hepatitis B in Canada and the United States has been to immunize the groups at high risk of infection (6). However, the failure of this vaccine in decreasing the overall incidence of acute hepatitis B in North America $(2,4)$, its limited and variable impact on reduc-

\section{REFERENCES}

1. Alter MJ, Coleman PJ, Alexander WJ, et al. The importance of heterosexual activity and intravenous drug use in the transmission of hepatitis B and non-A, non-B hepatitis. JAMA 1989;262:1201-3.

2. Centers for Disease Control. Protection against viral hepatitis: Recommendations of the Immunization Practices Advisory Committee (ACIP). MMWR 1990:39.

3. Hepatitis B in Canada: Surveillance summary, 1980-1989. Can Dis Wkly Rep 1991;17:166-71.

4. Alter MJ, Hadler SC, Margolis HS, et al. The changing epidemiology of hepatitis B in the United States. Need for alternative vaccination strategies. JAMA 1990;263:1218-22.

5. Centers for Disease Control, US Deparment of Health and Human Services, Public Health Service. Hepatitis surveillance: Report no 52, 1989.

6. National Advisory Committee on Immunization. Canadian Immunization Guide, 3rd edn. Ottawa: Department of National Health and Welfare, 1989:48-59.

7. Franks AL, Berg CJ, Kane MA, et al. Hepatitis B virus infection among children born in the United States to ing specific transmission patterns (7), the recognition that there are no identifiable risk factors in at least 30\% of patients (4), and the adoption of universal infant immunization programs in many developing countries $(8,9)$ has lead to a consensus that a universal immunization program against hepatitis B is required in North America as well. In Canada, the National Advisory Committee on Immunization and the Canadian Paediatric Society, and in the United States, the Immunization Practices Advisory Committee and the American Academy of Paediatrics have all recently endorsed a universal immunization strategy (10-12). A universal immunization program against hepatitis $\mathrm{B}$ for all preadolescents has been implemented recently in British Columbia. There are differences in opinion on the ideal timing of such a program, ie, in infancy, early adolescence or both, but, nonetheless, the paradigm shift with a move away from a targeted to a universal strategy has occurred.

Universal immunization against hepatitis B represents a unique situation because of the uncertainty regarding the duration of vaccine effectiveness and the unusual feature of the implementation of a health care policy with such a long term perspective. Nonetheless, the ultimate benefit of the universal immunization program would be the prevention of disease regardless of the time required to achieve this benefit.

Southeast Asian refugees. N Engl J Med 1989;321:1301-3.

8. Maynard JE. Hepatitis B: Global importance and need for control. Vaccine 1990;8(Suppl):518-20.

9. Buchan KA, Carter A, Gully P, Judson F, Robert J. Hepatitis B virus/sexually transmitted disease prevention strategies: An international perspective. Can J Infect Dis 1991;2(Suppl A):33A-7A.

10. National Advisory Committee an Immunization. Universal immunization against hepatitis B. Can Med Assoc $J$ 1992; 146:36.

11. Infectious Diseases and Immunization Committee, Canadian Paediatric Society. Hepatitis B in Canada: The case for universal immunization. Can Med Assoc J 1992;146:23-8.

12. Marwick C. Hapdtitis B vaccine appears loaded for paediatric immunization schedule. JAMA $1991 ; 265 ; 1502$.

John M Conly, MD Toronto, Ontario S Shafran, MD Edmonton, Alberta 


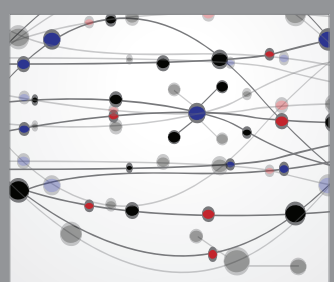

The Scientific World Journal
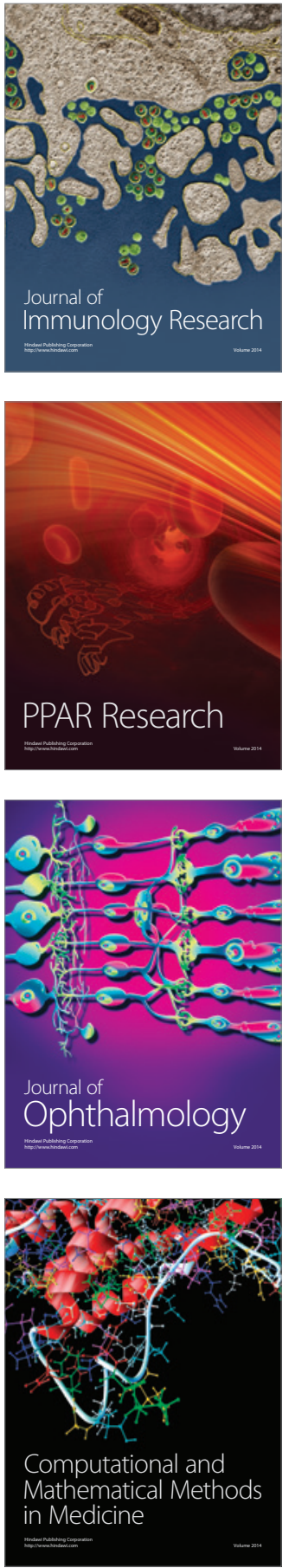

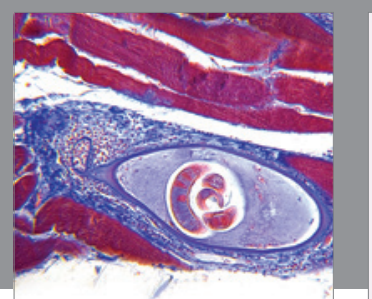

Gastroenterology Research and Practice

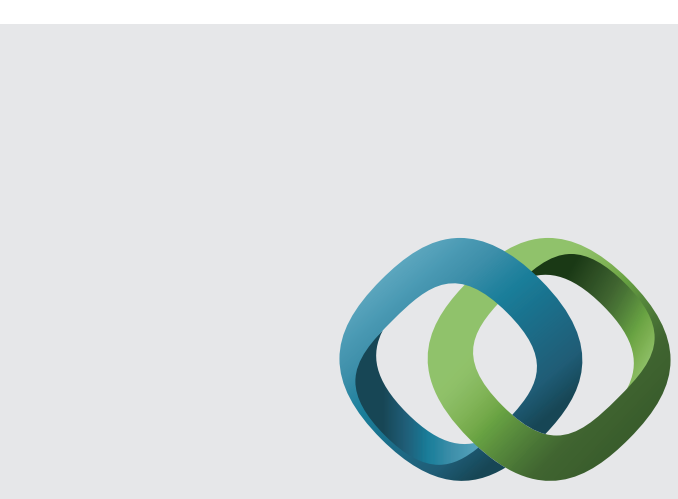

\section{Hindawi}

Submit your manuscripts at

http://www.hindawi.com
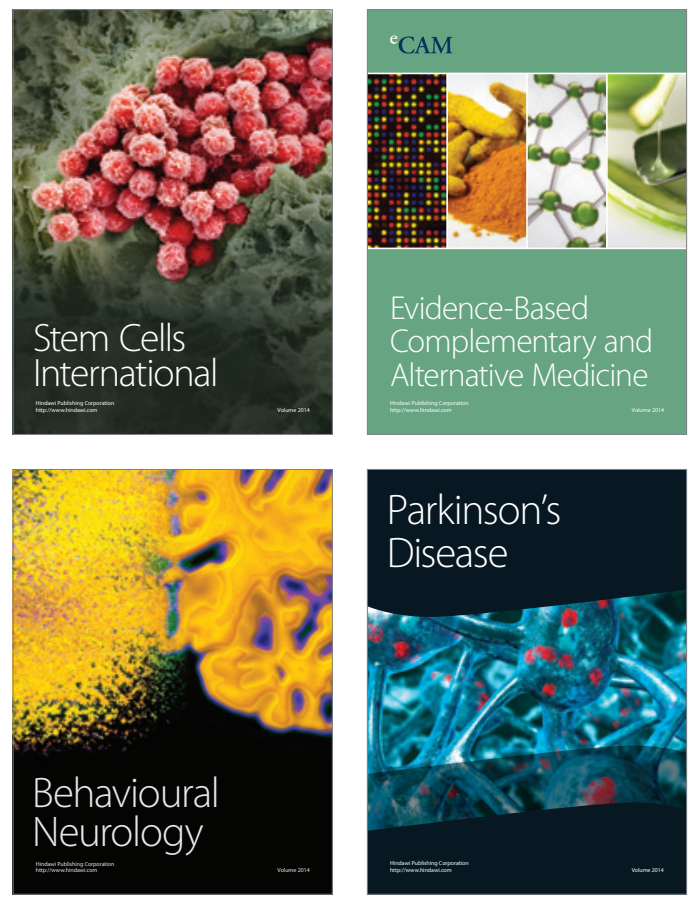
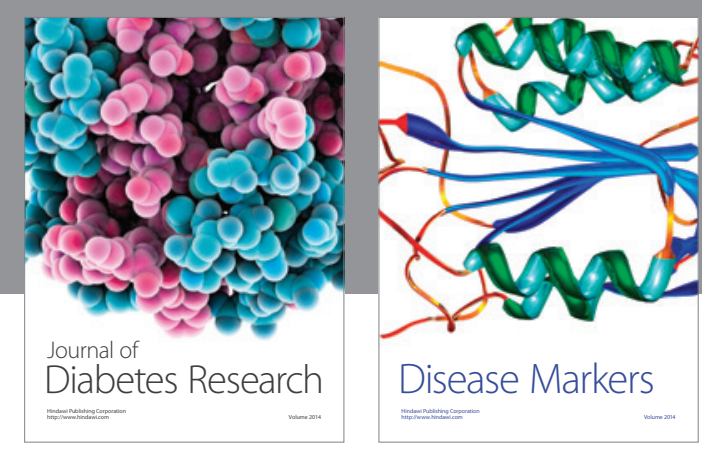

Disease Markers
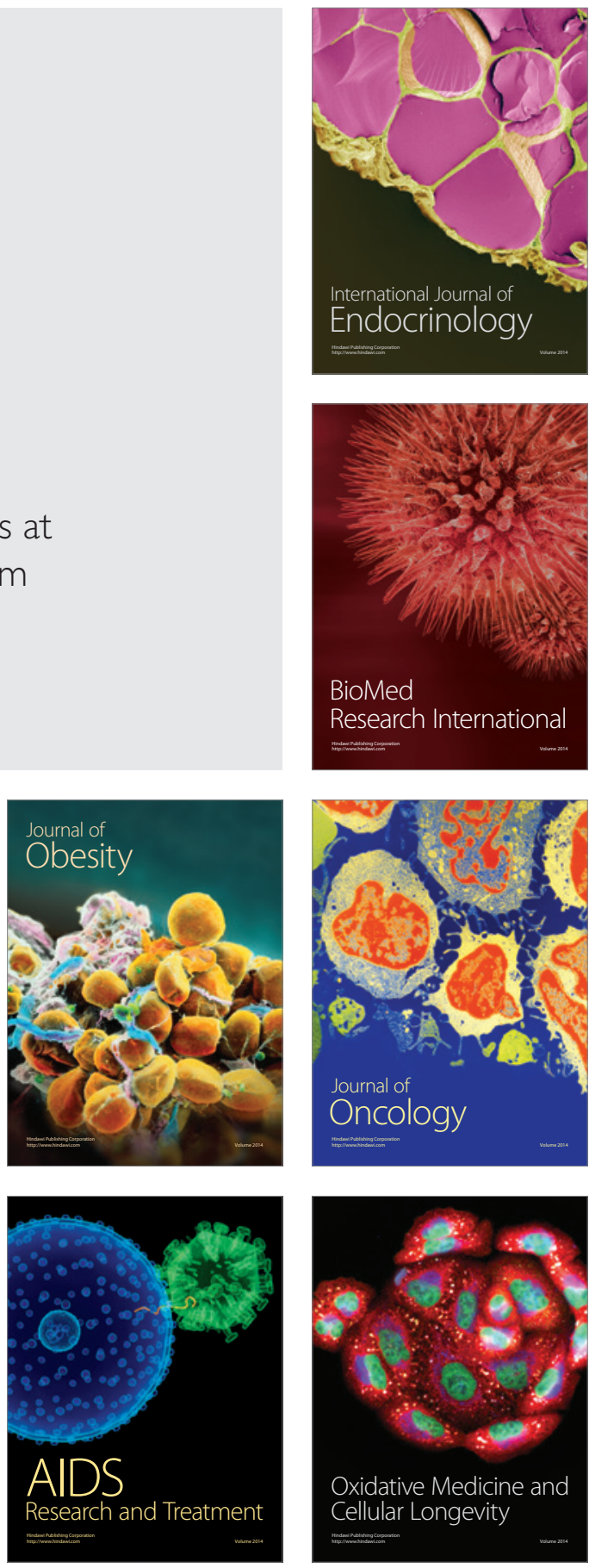